\section{RMD Open}

Rheumatic \&

Musculoskeletal Diseases

\title{
Knee joint synovitis: study of correlations and diagnostic performances of ultrasonography compared with histopathology
}

To cite: Najm A, Orr C, Gallagher L, et al. Knee joint synovitis: study of correlations and diagnostic performances of ultrasonography compared with histopathology. RMD Open 2018;4:e000616. doi:10.1136/ rmdopen-2017-000616

- Prepublication history for this paper is available online. To view these files, please visit the journal online (http://dx.doi. org/10.1136/rmdopen-2017000616).

Received 11 November 2017 Revised 25 December 2017 Accepted 29 December 2017

Check for updates

${ }^{1}$ Rheumatology Department, Centre Hospitalier Universitaire de Nantes, Nantes, Pays de la Loire, France

${ }^{2}$ The Centre for Arthritis and Rheumatic Diseases, Saint Vincent's University Hospital and Dublin Academic Medical Centre, University College Dublin, Dublin, Ireland ${ }^{3}$ Department of Molecular Rheumatology, Trinity College Dublin, Dublin, Ireland

Correspondence to Professor Douglas J Veale; douglas.veale@ucd.ie

\section{ABSTRACT}

Objectives Ultrasonography (US) is a fast, available and low-cost imaging tool used for detecting knee synovitis. Our aims were to assess the relationship between US and histology findings in appraising levels of inflammation and vascularity in the knee joint in subjects with inflammatory arthropathies; to determine whether differences exist in the appraisal between varying knee compartments and to compare US performances compared with gold standard histology for knee synovitis detection.

Methods Subjects with actively inflamed knee joint having crystal arthropathies, rheumatoid arthritis, psoriatic arthritis or ostoearthritis were prospectively recruited from rheumatology clinics after giving their written consent between May and October 2015. Study was approved by the institutional ethics committee. The knee was divided into three compartments (medial, lateral, superior). Patients had a knee US followed by a knee arthroscopy with biopsies retrieval from each compartment. Biopsies were blindly scored for lining layer hyperplasia, inflammation, vascularity, CD68 and factor VIII staining. Correlation was determined using the Spearman's correlation test.

Results 26 patients with active arthritis in a knee joint and recent onset of disease were prospectively included. Strong correlations were observed between US synovitis grade and histological inflammation score $(r=0.63$; $\mathrm{P}=0.002)$, US Doppler grade and histological score for vascularity $(r=0.68 ; P<0.001)$; US measured synovial thickness and lining layer hyperplasia $(r=0.61 ; P=0.002)$ Moderate correlation was found between US synovitis grade and CD68 score ( $r=0.49 ; \mathrm{P}=0.02)$.

Conclusion US findings correlate with histological inflammation and vascularity scores in actively inflamed knee joints. US accurately describes knee synovitis.

\section{INTRODUCTION}

Quantifying inflammation, disease activity and predicting joint destruction in rheumatic diseases remains a significant challenge.

Clinical examination remains important, and although this can contribute in assessing synovitis and predicting outcome, it remains insensitive for both these parameters. ${ }^{1}$

\section{Key messages}

What is already known about this subject?

- Correlations between US findings and some histological findings exist in small joints.

What does this study add?

- Correlations exists between US findings and histological findings such as inflammation score and CD68 staining, in knee joints.

How might this impact on clinical practice?

Ultrasonography in large joints such as knee is a reliable tool.

Ultrasonography (US) allows detection of active synovitis using B Mode for semiquantitative synovitis grade assignment and Doppler mode for hypervascularisation detection. ${ }^{2-4}$ Therefore, US examination allows the evaluation of disease activity ${ }^{5}$ and the determination of treatment efficacy. ${ }^{67}$ Some studies have assessed the reliability of US in appraising levels of joint inflammation. Karim et al have demonstrated that US examination is reproducible and has a better sensitivity $(98 \%)$, specificity $(88 \%)$, positive $(98 \%)$ and negative $(88 \%)$ predictive values than clinical examination, using arthroscopy as the gold standard. ${ }^{8}$ Other studies showed a better reliability of US examination compared with clinical assessment for synovitis detection in patients with rheumatoid arthritis (RA). ${ }^{910}$

MRI assessment of synovitis has been shown to correlate with histological inflammation in synovitis. ${ }^{11}$ MRI performances in prediction of both further diagnosis of RA in patients with undifferentiated arthritis (UA) and structural 
prognosis in established patients with RA have been demonstrated. ${ }^{12-14}$

Histological features such as levels of macrophage infiltration and lining layer hyperplasia are associated with disease activity and structural damages. ${ }^{15}$ Validated scores exist in order to assess and quantify histological inflammation within the synovial membrane. ${ }^{1617}$

Disease activity score 28 has been showed to correlate with histological inflammation of the synovial membrane. Indeed, sublining macrophages are considered a sensitive biomarker of response to treatment. ${ }^{18}$

However, synovial biopsies are not routinely performed in order to assess inflammation. In contrast, non-invasive imaging tools are routinely used.

US is widely performed and recognised as a reliable assessment tool for synovitis in rheumatology. However, only a few studies have assessed the correlation between Doppler mode features and histological vascularisation, and mostly in long-lasting RA populations. ${ }^{19-22}$ Moreover, it remains to be clarified whether US findings are a helpful biomarker for disease activity and possibly treatment response compared with synovial histology.

Our prospective study aimed to assess the correlation between US and histology findings in appraising levels of inflammation and vascularity in different areas of the knee joint in subjects with inflammatory arthropathies; to determine whether differences exist in the appraisal between varying knee compartments and to assess diagnostic performance of US measures for diagnosis of synovial inflammation compared with the histological gold standard.

\section{METHODS}

\section{Patients and methods}

Patients with an actively inflamed knee joint and recent onset of disease were consecutively recruited from the clinics of the Rheumatology Department, St. Vincent's University Hospital. All patients gave fully informed written consent for US evaluation and synovial biopsy by needle arthroscopy of the knee for research purposes as approved by the St. Vincent's Healthcare Group Medical Research and Ethics Committee.

All patients referred to outpatient clinics with an actively inflamed knee joint, having both UA or recently diagnosed with ostoearthritis (OA), autoimmune inflammatory arthropathy or crystal arthropathy were prospectively included from May to October 2015. All patients had an US examination of the knee joint immediately before undergoing arthroscopy of the same knee. The knee was divided into three compartments. The three compartments were defined as follows ${ }^{8}$ : medial compartment (MC) was defined as 'the area medial to the patella running inferiorly past the medial joint line to the inferomedial aspect of the joint capsule'. The lateral compartment (LC) was defined as 'the area lateral to the patella running inferiorly past the lateral joint line to the inferolateral aspect of the joint capsule'. The superior

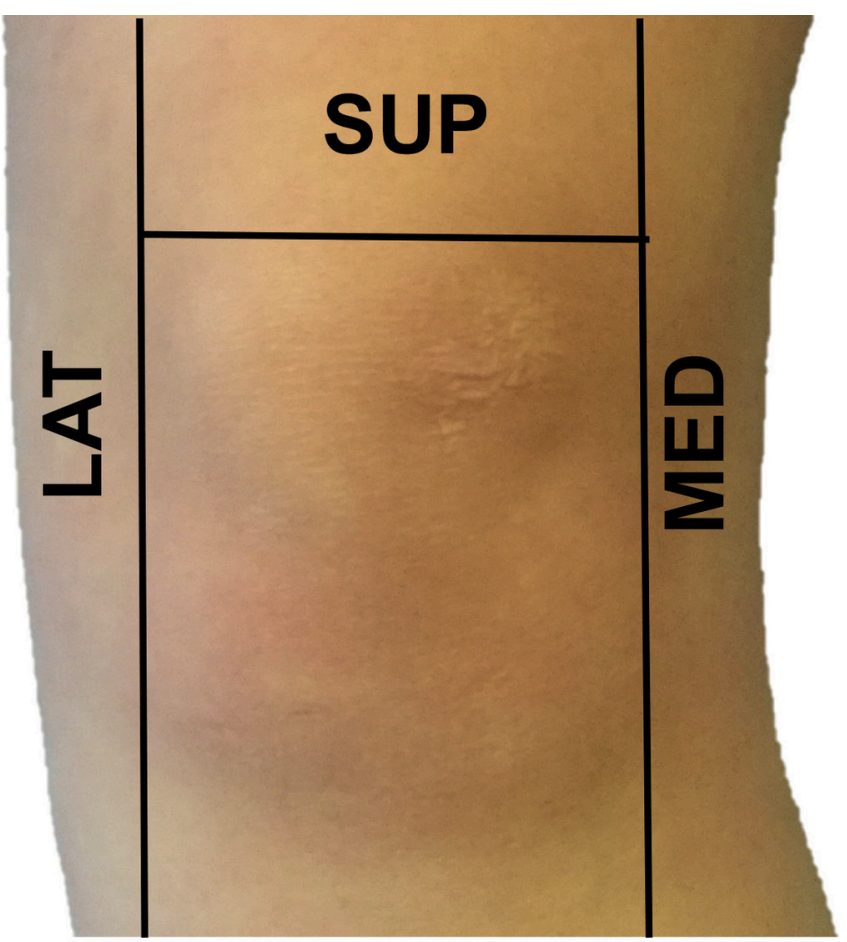

Figure 1 Illustration of the three major knee compartments as defined in our study. LAT, lateral; MED, medial; SUP, superior.

compartment (SC) was defined as 'the area above the patella' (figure 1).

\section{US evaluation}

One trained physician (3 years' experience) performed the US examination blindly from clinical data using a General Electrics Logiq 9 US machine with a 8-12 MHz linear transducer. US evaluation was performed on the knee in $20-30^{\circ}$ flexion according to the recommendations of the EULAR Musculoskeletal Ultrasound working group. A pulse repetition frequency of $750 \mathrm{~Hz}$ was used for power Doppler examination. Power Doppler signal (PDS) gain was set manually to a maximum of sensitivity just below the disappearance of colour noise.

Each compartment was scanned in longitudinal and lateral planes. $^{2}$ A well-established definition for joint effusion and synovial hypertrophy was used. ${ }^{23}$ The joint effusion evaluation was binary (present or not present). A cut-off limit of a longitudinal scan measure $>4 \mathrm{~mm}$ was used for pathological effusion definition. ${ }^{23}$ The evaluation for synovitis was performed using well-established semiquantitative scores with a four-grade scale of $0-3$ for both $\mathrm{B}$ mode and Doppler examination ${ }^{9}$ for each of the three compartments. Synovial thickness was measured with longitudinal scan for SC and transversal scans for MC and LC (figure 2).

B mode 0-3 grading for synovitis was $0=$ absence of synovial thickening, 1=mild synovial thickening, 2=moderate synovial thickening and $3=$ marked synovial thickening. Power Doppler activity was graded from 0 to 3 as follows: $0=$ absence of signal, no intra-articular flow; 

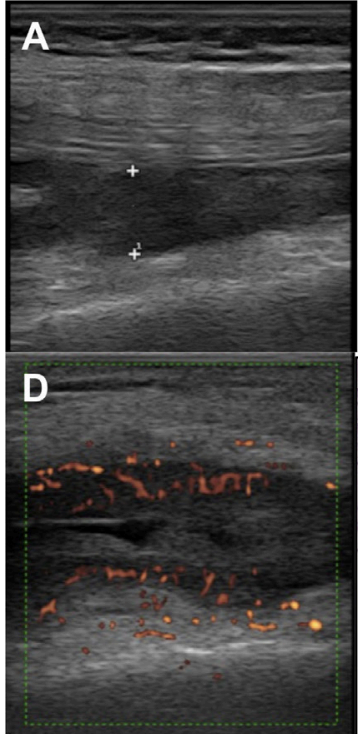

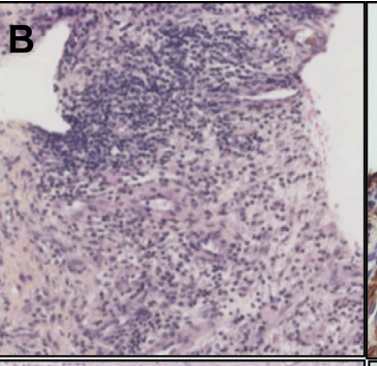

E
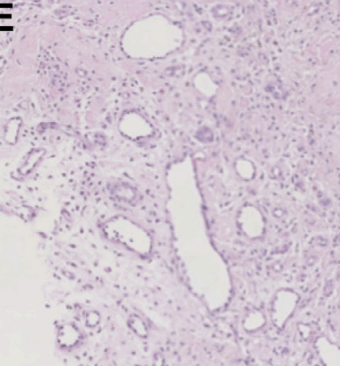

C
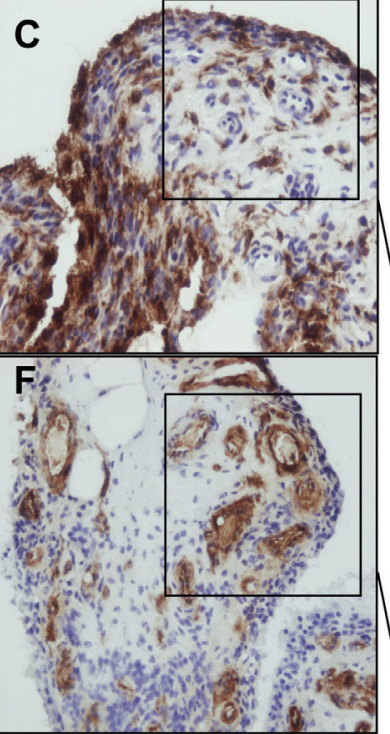
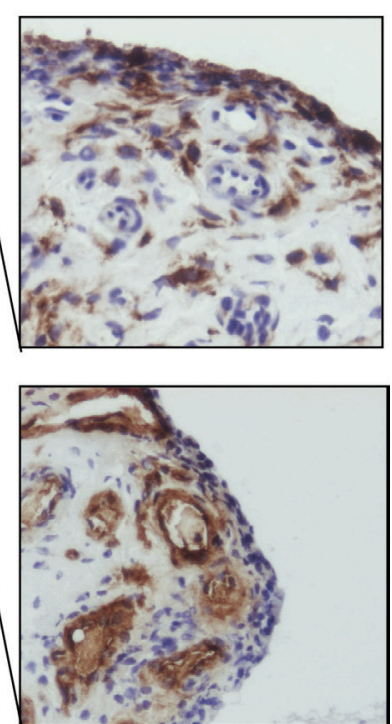

Figure 2 Example of ultrasound, histological and CD68 or factor VIII (FVIII) analyses. (A) B mode synovial thickness measurements. (B) H\&E stained slide. Histological synovitis: lining layer hyperplasia, stroma activation and inflammatory infiltrate. (C) Corresponding CD68 staining. Original magnification 20x. (D) Power Doppler activity assessment. (E) H\&E stained slide. Multiple blood vessels. (F) Corresponding FVIII staining. Original magnification 20x.

$1=$ mild (2-3 signals, including two confluent vessels); $2=$ moderate confluent vessels in $<50 \%$ of the synovium; and $3=$ marked vessel signals in $>50 \%$ of the synovium. ${ }^{910}$

The median of the scores attributed to each compartment was then calculated as an overall score for each patient.

\section{Arthroscopy}

Arthroscopy was performed by two trained experienced operators who were blinded from US findings, using a Wolf (Germany) or a Storz (Tuttlingen, Germany) $2.7 \mathrm{~mm}$ rigid arthroscope as previously described. ${ }^{24}$ The procedure was performed under local anaesthetic. Each compartment of the knee was marked according to previous definition before the procedure. Position of the arthroscope and forceps within the targeted compartment was ensured by transilluminating the skin with the arthroscope and impressing move under skin with forceps.

A $100 \mathrm{~mm}$ visual analogue scale (VAS) was used to score each compartment for both synovitis and vascularity. ${ }^{8} \mathrm{An}$ average of 20 biopsies were retrieved from each compartment and labelled.

The procedure was entirely recorded and stored for each patient.

\section{Biopsies processing and staining}

Tissue was fixed in formalin, embedded in paraffin and $3 \mu \mathrm{m}$ sectioned (Microtome). Sections were baked for $30 \mathrm{~min}$ at $90^{\circ} \mathrm{C}$, deparaffinised in xylene and dehydrated in alcohol and distilled water. Sections were then incubated with primary antibodies against human CD68 or human FVIII (Dako, Denmark) for 2 hours. Slides were then incubated with horseradish peroxidase-conjugated secondary antibody (Dako) for $30 \mathrm{~min}$. Diaminobenzidine tetrahydrochloride was used as the chromogene substrate (Dako). Slides were counterstained with haematoxylin (BDH Laboratories, Poole, UK) and mounted. Each slide was then scored by one trained experienced operator, blindly from US and arthroscopic findings, for inflammation and vascularisation using a semiquantitative five-scale score $(0=$ minimal infiltration, $1=$ mild infiltration, $2=$ moderate infiltration, $3=$ severe infiltration, $4=$ infiltration with numerous inflammatory cells)..$^{25-28}$ The lining layer hyperplasia was assessed by calculating the mean number of cell layers. CD68 slides were read and scored using a semiquantitative five-scale score for both lining layer and sublining calibrated against a standardised atlas. ${ }^{252628}$ The FVIII stained slides were scored by counting the absolute number of blood vessels per high-powered field (magnification $\times 20$ ) expressing FVIII. The score was the mean number calculated of five fields randomly selected ${ }^{29}$ (figure 2 ).

\section{Statistical analyses}

Normally distributed continuous data were expressed as the mean with SD or for non-normally distributed data as median with IQR. Professional statistician was consulted for statistical design. Correlation were studied using the Spearman's correlation tests. When the correlation coefficient was $r<0.3$, correlation was considered as mild. When comprised between $0.3<\mathrm{r}<0.6$, the correlation strength was considered as moderate. When the correlation coefficient was comprised between $r>0.6$, the correlation strength was considered as high. A P value $<0.05$ was considered statistically significant. Correlation analyses were performed through GraphPad Prism V.6.0.

Sensitivity, specificity, predictive positive and negative values of US to detect inflammatory arthritis compared 


\begin{tabular}{|c|c|c|}
\hline & $\mathbf{N}$ & \\
\hline Total & 26 & \\
\hline \multicolumn{3}{|l|}{ Demographics } \\
\hline \multicolumn{3}{|l|}{ Gender } \\
\hline Female & 21 & $80.8 \%$ \\
\hline Mean age (years) (range) & 50.8 & $(31.3-68.2)$ \\
\hline $\begin{array}{l}\text { Female mean age (years) } \\
\text { (range) }\end{array}$ & 50.8 & $(31.3-68.2)$ \\
\hline Male mean age (years) (range) & 50.7 & $(35-57.9)$ \\
\hline \multicolumn{3}{|l|}{ Biopsied knee } \\
\hline Right & 13 & $50.0 \%$ \\
\hline \multicolumn{3}{|l|}{ Diagnosis } \\
\hline $\mathrm{RA}$ & 17 & $65.4 \%$ \\
\hline $\begin{array}{l}\text { Rheumatoid factor } \\
\text { positive }\end{array}$ & 10 & $38.6 \%$ \\
\hline Anti-CCP positive & 12 & $46.2 \%$ \\
\hline DAS 28 (mean) (SD) & 3.85 & $(1.03)$ \\
\hline PsA & 3 & $11.5 \%$ \\
\hline $\mathrm{OA}$ & 4 & $15.4 \%$ \\
\hline Gout & 1 & $3.8 \%$ \\
\hline UA & 1 & $3.8 \%$ \\
\hline Elevated CRP (> 5 mg/L) & 14 & $53.8 \%$ \\
\hline Erosive disease (RA) & 4 & $15.4 \%$ \\
\hline \multicolumn{3}{|l|}{ Treatment (RA. PsA) } \\
\hline Methotrexate & 3 & $11.5 \%$ \\
\hline TNF inhibitors & 4 & $15.4 \%$ \\
\hline Other & 1 & $3.8 \%$ \\
\hline
\end{tabular}

CCP, cyclic citrullinated peptides; CRP, $\mathrm{C}$ reactive protein; DAS, dsease activity score; OA, ostoearthritis; PsA, psoriatic arthritis; RA, rheumatoid arthritis; TNF, tumour necrosis factor. with histological gold standard were calculated through SPSS software.

\section{RESULTS}

\section{Patients' characteristics}

Twenty-six patients were included between May and October 2015 in Saint Vincent's University Hospital. Demographic and clinical characteristics of the patients are shown in table 1 .

\section{US, arthroscopic and histological scores}

Median US synovitis grade was 1 (0-2). Median measured synovial thickness was $1.6 \mathrm{~mm}(1.1-3.2)$. Median histological scores and CD68 and FVIII scores are shown in table 2.

\section{Correlation between US and histological scores \\ US and histology}

In the LCs, we found strong correlations between US B mode synovitis score and histological inflammation score $(\mathrm{r}=0.67 ; \mathrm{P}=0.013)$, and between US measured synovial thickness and histological score for lining layer hyperplasia ( $\mathrm{r}=0.55 ; \mathrm{P}=0.038)$.

In the SC and MC, correlations between US B mode synovitis score and histological inflammation score, and between US measured synovial thickness and histological score for lining layer hyperplasia did not reach statistical significance (table 3 ).

Median scores represent the median of for lateral, medial and superior scores.

Strong correlations were observed between median US $B$ mode synovitis score and median histological inflammation score $(\mathrm{r}=0.63 ; \mathrm{P}=0.001)$; median US measured synovial thickness and median histological lining layer hyperplasia score $(\mathrm{r}=0.61 ; \mathrm{P}=0.002)$; and median US power Doppler score and median histological vascularisation score $(\mathrm{r}=0.68 ; \mathrm{P}=0.0003)$ (table 3$)$.

Table 2 Ultrasonography (US) and histological findings

\begin{tabular}{|c|c|c|c|c|}
\hline & Superior & Lateral & Medial & $\begin{array}{l}\text { Mean overall } \\
\text { score* }^{*}\end{array}$ \\
\hline $\begin{array}{l}\text { Median US synovitis grade } \\
\text { (0-3 semiquantitative score) (Q1-Q3) }\end{array}$ & $1(0-2)$ & $1(1-2)$ & $1(0-2)$ & $1(0-2)$ \\
\hline $\begin{array}{l}\text { Median measured synovial thickness }(\mathrm{mm}) \\
\text { (Q1-Q3) }\end{array}$ & $1.55(0.8-4.3)$ & $2.1(1.3-3.1)$ & $2.05(0.3-3.4)$ & $1.6(1.1-3.2)$ \\
\hline $\begin{array}{l}\text { Median US synovitis grade (Doppler mode) } \\
\text { (0-3 semiquantitative score) } \\
\text { (Q1-Q3) }\end{array}$ & $0(0-2)$ & $0(0-1)$ & $0(0-2)$ & $0(0-2)$ \\
\hline $\begin{array}{l}\text { Median histological synovitis score (0-4) } \\
\text { (Q1-Q3) }\end{array}$ & $2(1-2)$ & $1(1-2.8)$ & $2(1-3)$ & $2(1-2.5)$ \\
\hline $\begin{array}{l}\text { Median CD68 score } \\
\text { (Q1-Q3) }\end{array}$ & $3(2.75-4)$ & $3(2-3)$ & $3(2-3)$ & $3(2-3.5)$ \\
\hline $\begin{array}{l}\text { Mean number of vessels per slide (absolute number } \\
\text { with FVIII staining) (SD) }\end{array}$ & $8.3(5.4)$ & $11(6.3)$ & $16(8.0)$ & $10.2(6.3)$ \\
\hline
\end{tabular}

${ }^{*}$ Overall scores are the mean scores of the three compartments.

FVIII, factor VIII staining; Q1-Q3, first and third quartiles. 
US and immunohistochemistry

In the SC, LC and MC, correlations between US B mode synovitis score or US measured synovial thickness and CD68 staining did not reach statistical significance (table 3).

However, moderate correlation was observed between median US B mode synovitis score and median score for CD68 staining ( $\mathrm{r}=0.49 ; \mathrm{P}=0.02)$; strong correlations were observed between median US measured synovial thickness and median score for CD68 staining $(\mathrm{r}=0.59 ; \mathrm{P}=0.006)$ (table 3$)$.

In the LC, significant strong correlation was found between US power Doppler score and FVIII staining $(\mathrm{r}=0.74 ; \mathrm{P}=0.009)$. However, median US power Doppler score and median FVIII staining did not reach statistical significance (table 3 ).

Correlation between the three knee compartments for US, arthroscopic and histological findings

Strong correlations were observed between the SC, $\mathrm{MC}$ and LC of the knee for US synovitis grade and US measured synovial thickness (table 4). However, power Doppler grade partially correlates only (table 4).
Moderate to high correlations were found between SC and LC, LC and MC for synovitis and vascularity $0-100$ VAS score (table 4)

However, the correlation found between SC and MC was not significant $(\mathrm{r}=0.31 ; \mathrm{P}=0.12$ for synovitis and $\mathrm{r}=0.24 ; \mathrm{P}=0.24$ for vascularity).

Regarding histological analysis, strong correlation was found between SC, MC, LC and median scores for inflammation, lining layer thickness and vascularisation scores (table 4).

\section{Diagnostic performance of US in recognising inflammatory} arthritis compared with gold standard histology

For inflammatory arthritis recognition, US B mode had a sensitivity of $42 \%$ (95\% confidence interval (CI) $(13.77 \%$; $69.56 \%))$, a specificity of $90 \%$ (95\% CI $(71.41 \%$; $108.6 \%)$ ), a negative predictive value (NPV) of $56.25 \%$ $(95 \%$ CI $(31.94 \% ; 80.56 \%))$ and a predictive positive value (PPV) of $83.3 \%$ (9\% CI 5 (53.51\%; 113.2\%)) compared with histological gold standard.

For inflammatory arthritis recognition, US Doppler mode had a sensitivity of $10 \%(95 \%$ CI $(8.59 \%$; $28.59 \%))$, a specificity of $91.16 \%$ (76.03\%; $107.3 \%)$, an NPV $57.14 \%$

Table 3 Correlation between ultrasonography and histological findings

\begin{tabular}{|c|c|c|c|}
\hline & $\begin{array}{l}\text { B mode synovitis } \\
\text { grade }(r)\end{array}$ & $\begin{array}{l}\text { B mode synovial } \\
\text { thickness ( } r \text { ) }\end{array}$ & $\begin{array}{l}\text { Power Doppler } \\
\text { grade (r) }\end{array}$ \\
\hline \multicolumn{4}{|l|}{ Superior } \\
\hline Histological inflammation score & $0.48 \dagger$ & 0.35 & 0.27 \\
\hline Histological lining layer thickness score & $0.48 \dagger$ & $0.44 \dagger$ & 0.23 \\
\hline Histological vascularisation score & 0.42 & 0.38 & 0.17 \\
\hline CD68 score & $0.42 \dagger$ & 0.37 & 0.20 \\
\hline FVIII score & 0.38 & 0.18 & 0.27 \\
\hline \multicolumn{4}{|l|}{ Medial } \\
\hline Histological inflammation score & 0.24 & 0.26 & 0.11 \\
\hline Histological lining layer thickness score & $0.53^{*}$ & $0.44 \dagger$ & 0.22 \\
\hline Histological vascularisation score & 0.23 & 0.16 & 0.13 \\
\hline CD68 score & $0.45 \dagger$ & $0.49 \dagger$ & $0.52^{*}$ \\
\hline FVIII score & 0.27 & 0.15 & 0.22 \\
\hline \multicolumn{4}{|l|}{ Lateral } \\
\hline Histological inflammation score & $0.67^{*}$ & $0.69^{*}$ & $0.65^{\star}$ \\
\hline Histological lining layer thickness score & $0.55^{\star}$ & $0.69^{*}$ & $0.66^{*}$ \\
\hline Histological vascularisation score & $0.77^{\star}$ & $0.88^{\star \star}$ & $0.61^{*}$ \\
\hline CD68 score & $0.50 \dagger$ & $0.48^{*}$ & 0.30 \\
\hline FVIII score & $0.78^{*}$ & $0.84^{*}$ & $0.74^{*}$ \\
\hline \multicolumn{4}{|l|}{ Overall median scores } \\
\hline Histological inflammation score & $0.63^{\star}$ & $0.65^{\star *}$ & $0.62^{*}$ \\
\hline Histological lining layer thickness score & $0.64^{*}$ & $0.61^{*}$ & $0.77^{\star \star}$ \\
\hline Histological vascularisation score & $0.60^{*}$ & $0.57^{*}$ & $0.68^{\star *}$ \\
\hline CD68 score & $0.49^{\star}$ & $0.59^{*}$ & $0.63^{*}$ \\
\hline FVIII score & 0.36 & $0.41 \dagger$ & 0.33 \\
\hline
\end{tabular}

$\dagger \mathrm{P}<0.1 ;{ }^{*} \mathrm{P}<0.05 ;{ }^{* \star} \mathrm{P}<0.001 ;{ }^{* \star *} \mathrm{P}<0.0001$.

FVIII, factor VIII staining; $r$, correlation coefficient. 
Table 4 Correlation for ultrasonography, arthroscopic, histological and immunohistological findings between the three major compartments of the knee

\begin{tabular}{|c|c|c|c|}
\hline \multicolumn{4}{|l|}{ Ultrasonography } \\
\hline & Synovitis grade (r) & Thickness (r) & Power Doppler grade (r) \\
\hline Superior and lateral & $0.62^{\star \star}$ & $0.65^{\star \star *}$ & 0.15 \\
\hline Superior and medial & $0.61^{*}$ & $0.48^{\star}$ & 0.15 \\
\hline Medial and lateral & $0.75^{\star \star \star}$ & $0.73^{\star \star \star}$ & $0.44^{*}$ \\
\hline Superior and overall & $0.75^{\star \star \star}$ & $0.87^{\star \star \star}$ & $0.47^{\star}$ \\
\hline Medial and overall & $0.86^{\star \star \star}$ & $0.87^{\star \star \star}$ & $0.71^{\star \star \star}$ \\
\hline Lateral and overall & $0.82^{\star \star \star}$ & $0.80^{\star \star \star}$ & $0.64^{* *}$ \\
\hline \multicolumn{4}{|l|}{ Arthroscopy } \\
\hline & Synovitis (r) & Vascularity (r) & \\
\hline Superior and lateral & $0.60^{*}$ & $0.51^{*}$ & \\
\hline Superior and medial & 0.31 & 0.24 & \\
\hline Medial and lateral & $0.44^{*}$ & $0.58^{*}$ & \\
\hline Superior and overall & $0.79^{\star \star \star}$ & $0.62^{*}$ & \\
\hline Medial and overall & $0.85^{\star \star \star}$ & $0.83^{\star \star \star}$ & \\
\hline Lateral and overall & $0.69^{\star \star \star}$ & $0.75^{\star \star *}$ & \\
\hline \multicolumn{4}{|l|}{ Histology } \\
\hline & Inflammation (r) & Lining layer thickness (r) & Vascularisation (r) \\
\hline Superior and lateral & $0.47 \dagger$ & $0.78^{*}$ & $0.64^{*}$ \\
\hline Superior and medial & $0.69^{\star}$ & $0.69^{\star}$ & $0.44 \dagger$ \\
\hline Medial and lateral & $0.68^{*}$ & $0.95^{\star \star \star}$ & $0.51 \dagger$ \\
\hline Superior and overall & $0.82^{\star \star \star}$ & $0.89^{\star \star \star}$ & $0.89^{\star \star \star}$ \\
\hline Medial and overall & $0.93^{* *}$ & $0.94^{\star \star \star}$ & $0.74^{\star \star \star}$ \\
\hline Lateral and overall & $0.70^{*}$ & $0.90^{\star \star \star}$ & $0.79^{\star * \star}$ \\
\hline \multicolumn{4}{|c|}{ Immunohistochemistry } \\
\hline & CD68 (r) & FVIII (r) & \\
\hline Superior and lateral & 0.28 & $0.83^{*}$ & \\
\hline Superior and medial & 0.49 & $0.71 \dagger$ & \\
\hline Medial and lateral & 0.34 & 0.61 & \\
\hline Superior and overall & $0.85^{\star \star}$ & $0.85^{\star \star}$ & \\
\hline Medial and overall & $0.82^{\star \star \star}$ & $0.83^{\star *}$ & \\
\hline Lateral and overall & $0.78^{\star \star}$ & $0.73^{\star}$ & \\
\hline
\end{tabular}

$\dagger \mathrm{P}<0.1$; ${ }^{*} \mathrm{P}<0.05 ;{ }^{* *} \mathrm{P}<0.001$; ${ }^{* * *} \mathrm{P}<0.0001$.

FVIII, Factor VIII staining; $r$, correlation coefficient.

$(35.98 \% ; 78.31 \%)$ compared with standard vascularity histological assessment.

\section{DISCUSSION}

Our study is the first to assess correlations for knee synovitis, between US evaluation and histological findings for both B mode and Doppler examination. To date, no study has demonstrated the correlation between B mode semiquantitative synovitis score and both histological H\&E stained slides and CD68 staining findings. Given the existing variability of US and histological findings between compartments within the same joint, correlations were not always significant at the compartment level.
However, when combined in median scores, moderate to strong correlations were found.

In the literature, controversial results have been described. Anandarajah et $a \hat{l}^{30}$ found no significant correlation between US findings and histological findings for synovitis in 15 patients with RA. However, the patients were in remission and the synovial tissue was retrieved during arthroplasty, which may reflect a different, more long-standing disease phenotype. Such synovial tissue may differ from that retrieved in patients with early arthritis, and in our cohort, $70 \%$ of the patients (18/26) were untreated at the time of arthroscopy, and the duration of the symptoms ranged from 6 weeks to 6 months. 
Schmidt et al, described association between US PDS and presence or absence of histological pannus. ${ }^{20}$ Walther $e t$ $a l$, showed a strong correlation $(\mathrm{r}=0.89 ; \mathrm{P}<0.01)$ between power Doppler semiquantitative score and the histological qualitative score given by the pathologist after FVIII staining. ${ }^{21}$ However, in another study involving 44 subjects using power Doppler evaluation on several joints followed by biopsy, no correlation was found between global inflammation score or blood vessel proliferation. ${ }^{19}$ Andersen et al showed a correlation between Doppler colour fraction and overall synovitis score, CD68, CD3, von Willebrand factor in wrists and finger joints, despite finding. ${ }^{31}$

Kelly et al showed a good correlation between PDS, histological vascular area and angiogenic factors. ${ }^{22}$

In our work, in respect of vascularity, the correlation between power Doppler score and FVIII staining was not statistically significant. This may be due to a lack of power due to the relatively small cohort. Moreover, only a few patients $(4 / 26,15,4 \%)$ had a positive Doppler activity. This might be explained by the known limited sensitivity of Doppler mode for relatively deep anatomic areas, such as knee joints.

A strong correlation was found between power Doppler grade of the synovitis and histological inflammation score, lining layer hyperplasia score and vascularisation score.

Our study assessed the correlation between US, arthroscopic and histological findings in the three major compartments of the knee joint. This is the first study assessing the correlation between histological features of the synovial membrane in three well-defined different areas of the knee joint. Indeed, all parameters in each compartment had a moderate to strong correlation with median overall scores. This was also true between LC, MC and SC for US B mode synovitis and measured synovial thickness, for histology and for arthroscopy (although not significant for the SC and $\mathrm{MC}$ ). However, correlations between MC, LC and SC for CD68 or FVIII staining were not statistically significant.

Our findings suggest that in comparative studies of imaging methods using histology as the reference standard synovial biopsies need to be retrieved from the three major compartments of the knee as the correlations strengthen when each compartment score is compared with the overall median score. In individual compartments, the lack of correlation in some findings could be related to the variability of the findings at the compartment level.

Our work used two different and complementary approaches. After assessing correlations, we explored diagnostic performances of US to detect inflammatory arthropathies using histology as the gold standard. Interestingly, the specificity of US was approximately $90 \%$ for both B mode and Doppler mode compared with histological assessment of both inflammation and vascularity. This re-ensures the use of US in detecting synovitis for both diagnosis and response to treatment assessment.
However, $10 \%$ of the patients having a normal US examination in our cohort still exhibit histological signs of inflammation in their synovial biopsies.

We acknowledge that our work has limitations, the small number of patients in our prospective cohort is one of them. To address this issue, we used non-parametric correlation tests after confirming with professional statistician that results obtained will be generalisable. Indeed, the severity of synovitis in the analysed sample was in general rather low.

In conclusion, we have demonstrated that US examination with both B mode and power Doppler reflects accurately histological inflammation and vascularisation, as well as commonly used CD68 staining in knee synovitis.

Contributors AN, CO, DJV, EG and BLG contributed to the planning of the work described in the article. AN, MB, LG, UF and DJV contributed to the conduction of the work described in the article. All authors contributed to the reporting of the work described in the article and approved its final version.

Funding This research received no specific grant from any funding agency in the public, commercial or not-for-profit sectors.

Competing interests None declared.

Patient consent Obtained.

Ethics approval This work was approved by St. Vincent's Healthcare Group Medical Research and Ethics Committee.

Provenance and peer review Not commissioned; externally peer reviewed. Data sharing statement No additional unpublished data are available.

Open Access This is an Open Access article distributed in accordance with the Creative Commons Attribution Non Commercial (CC BY-NC 4.0) license, which permits others to distribute, remix, adapt, build upon this work non-commercially, and license their derivative works on different terms, provided the original work is properly cited and the use is non-commercial. See: http://creativecommons.org/ licenses/by-nc/4.0/

(C) Article author(s) (or their employer(s) unless otherwise stated in the text of the article) 2018. All rights reserved. No commercial use is permitted unless otherwise expressly granted.

\section{REFERENCES}

1. Emery P, Breedveld FC, Dougados M, et al. Early referral recommendation for newly diagnosed rheumatoid arthritis: evidence based development of a clinical guide. Ann Rheum Dis 2002;61:290-7.

2. Backhaus M, Burmester GR, Gerber T, et al. Guidelines for musculoskeletal ultrasound in rheumatology. Ann Rheum Dis 2001;60:641-9.

3. Carotti M, Salaffi F, Manganelli P, et al. Power Doppler sonography in the assessment of synovial tissue of the knee joint in rheumatoid arthritis: a preliminary experience. Ann Rheum Dis 2002;61:877-82.

4. Dougados M, Jousse-Joulin S, Mistretta F, et al. Evaluation of several ultrasonography scoring systems for synovitis and comparison to clinical examination: results from a prospective multicentre study of rheumatoid arthritis. Ann Rheum Dis 2010;69:828-33.

5. Chakr RM, Mendonça JA, Brenol CV, et al. Assessing rheumatoid arthritis disease activity with ultrasound. Clin Rheumatol 2013;32:1249-54.

6. Albrecht K, Grob K, Lange U, et al. Reliability of different Doppler ultrasound quantification methods and devices in the assessment of therapeutic response in arthritis. Rheumatology 2008;47:1521-6.

7. Fiocco U, Ferro F, Vezzù M, et al. Rheumatoid and psoriatic knee synovitis: clinical, grey scale, and power Doppler ultrasound assessment of the response to etanercept. Ann Rheum Dis 2005;64:899-905.

8. Karim Z, Wakefield RJ, Quinn M, et al. Validation and reproducibility of ultrasonography in the detection of synovitis in the knee: a comparison with arthroscopy and clinical examination. Arthritis Rheum 2004;50:387-94. 
9. Mandl P, Balint PV, Brault Y, et al. Metrologic properties of ultrasound versus clinical evaluation of synovitis in rheumatoid arthritis: results of a multicenter, randomized study. Arthritis Rheum 2012;64:1272-82.

10. Naredo E, Bonilla G, Gamero F, et al. Assessment of inflammatory activity in rheumatoid arthritis: a comparative study of clinical evaluation with grey scale and power Doppler ultrasonography. Ann Rheum Dis 2005;64:375-81.

11. de Lange-Brokaar BJ, loan-Facsinay A, Yusuf E, et al. Degree of synovitis on MRI by comprehensive whole knee semi-quantitative scoring method correlates with histologic and macroscopic features of synovial tissue inflammation in knee osteoarthritis. Osteoarthritis Cartilage 2014;22:1606-13.

12. Duer-Jensen A, Hørslev-Petersen $\mathrm{K}$, Hetland ML, et al. Bone edema on magnetic resonance imaging is an independent predictor of rheumatoid arthritis development in patients with early undifferentiated arthritis. Arthritis Rheum 2011;63:2192-202.

13. Baker JF, Ostergaard M, Emery P, et al. Early MRI measures independently predict 1-year and 2-year radiographic progression in rheumatoid arthritis: secondary analysis from a large clinical trial. Ann Rheum Dis 2014;73:1968-74.

14. Baker JF, Conaghan PG, Smolen JS, et al. Development and validation of modified disease activity scores in rheumatoid arthritis: superior correlation with magnetic resonance imaging-detected synovitis and radiographic progression. Arthritis Rheumatol 2014;66:794-802.

15. Kraan MC, Versendaal $\mathrm{H}$, Jonker $\mathrm{M}$, et al. Asymptomatic synovitis precedes clinically manifest arthritis. Arthritis Rheum 1998;41:1481-8

16. Krenn V, Morawietz L, Burmester GR, et al. Synovitis score: discrimination between chronic low-grade and high-grade synovitis. Histopathology 2006;49:358-64.

17. Krenn V, Morawietz L, Häupl T, et al. Grading of chronic synovitis - a histopathological grading system for molecular and diagnostic pathology. Pathol Res Pract 2002;198:317-25.

18. Bresnihan B, Pontifex E, Thurlings RM, et al. Synovial tissue sublining CD68 expression is a biomarker of therapeutic response in rheumatoid arthritis clinical trials: consistency across centers. $J$ Rheumatol 2009;36:1800-2.

19. Koski JM, Saarakkala S, Helle M, et al. Power Doppler ultrasonography and synovitis: correlating ultrasound imaging with histopathological findings and evaluating the performance of ultrasound equipments. Ann Rheum Dis 2006;65:1590-5.
20. Schmidt WA, Völker L, Zacher J, et al. Colour Doppler ultrasonography to detect pannus in knee joint synovitis. Clin Exp Rheumatol 2000;18:439-44.

21. Walther M, Harms H, Krenn V, et al. Correlation of power Doppler sonography with vascularity of the synovial tissue of the knee joint in patients with osteoarthritis and rheumatoid arthritis. Arthritis Rheum 2001:44:331-8.

22. Kelly S, Bombardieri M, Humby F, et al. Angiogenic gene expression and vascular density are reflected in ultrasonographic features of synovitis in early Rheumatoid Arthritis: an observational study. Arthritis Res Ther 2015;17:58.

23. D'Agostino MA, Conaghan P, Le Bars M, et al. EULAR report on the use of ultrasonography in painful knee osteoarthritis. Part 1: prevalence of inflammation in osteoarthritis. Ann Rheum Dis 2005;64:1703-9.

24. Fearon U, Griosios K, Fraser A, et al. Angiopoietins, growth factors, and vascular morphology in early arthritis. J Rheumatol 2003;30:260-8.

25. Tak PP, Smeets TJ, Daha MR, et al. Analysis of the synovial cell infiltrate in early rheumatoid synovial tissue in relation to local disease activity. Arthritis Rheum 1997;40:217-25.

26. Tak PP, Thurkow EW, Daha MR, et al. Expression of adhesion molecules in early rheumatoid synovial tissue. Clin Immunol Immunopathol 1995;77:236-42.

27. Tak PP, van der Lubbe PA, Cauli A, et al. Reduction of synovial inflammation after anti-CD4 monoclonal antibody treatment in early rheumatoid arthritis. Arthritis Rheum 1995;38:1457-65.

28. Tak PP, Taylor PC, Breedveld FC, et al. Decrease in cellularity and expression of adhesion molecules by anti-tumor necrosis factor alpha monoclonal antibody treatment in patients with rheumatoid arthritis. Arthritis Rheum 1996;39:1077-81.

29. Kennedy $\mathrm{A}, \mathrm{Ng} \mathrm{CT}$, Biniecka $\mathrm{M}$, et al. Angiogenesis and blood vessel stability in inflammatory arthritis. Arthritis Rheum 2010;62:711-21.

30. Anandarajah A, Thiele R, Giampoli E, et al. Patients with rheumatoid arthritis in clinical remission manifest persistent joint inflammation on histology and imaging studies. J Rheumatol 2014;41:2153-60.

31. Andersen M, Ellegaard K, Hebsgaard JB, et al. Ultrasound colour Doppler is associated with synovial pathology in biopsies from hand joints in rheumatoid arthritis patients: a cross-sectional study. Ann Rheum Dis 2014;73:678-83. 